\title{
ANTIOXIDANT ACTIVITY OF THE AQUEOUS AND METHANOLIC EXTRACTS OF COFFEE BEANS (COFFEA ARABICA L.)
}

\author{
Urszula Złotek, Monika Karaś, Urszula Gawlik-Dziki, Urszula Szymanowska ${ }^{\bowtie}$, \\ Barbara Baraniak, Anna Jakubczyk
}

Department of Biochemistry and Food Chemistry, University of Life Sciences in Lublin Skromna 8, 20-704 Lublin, Poland

\begin{abstract}
Background. Coffee is important source of natural antioxidants in the diet, such as phenolic compounds, alkaloids, mainly caffeine, diterpenes (cafestol and kahweol) and Maillard reaction products formed during roasting.

Material and methods. In aqueous and methanolic extracts of coffee (Coffea arabica L.) roasted using traditional techniques from Brazil (B), Colombia (C), Ethiopia (E), Kenya (K) and coffee roasted using an industrial technique from Brazil (T), the phenolic and caffeine content as well as antioxidant properties were determined.

Results. Comparing the results from water and methanolic extracts it should be noted that the highest amount of phenolics was determined for a methanolic extract of coffee roasted using the industrial technique (650.96 $\mathrm{mg} \mathrm{GAE} / \mathrm{g} \mathrm{DW}$ ) and a water extract of Kenya coffee (461.63 mg GAE/g DW). Caffeine content was on average two times higher in all methanolic extracts than in water extracts. The radical scavenging activity of aqueous extracts was found to be higher than methanolic extracts. The highest antioxidant scavenging activity was determined for $\mathrm{C}\left(\mathrm{EC}_{50}=1.16 \mathrm{mg} \mathrm{DW} / \mathrm{ml}\right)$ and $\mathrm{E}\left(\mathrm{EC}_{50}=1.3 \mathrm{mg} \mathrm{DW} / \mathrm{ml}\right)$ water extracts. Compared to water extracts methanolic extracts showed significantly higher reducing power, ability to chelate $\mathrm{Fe}^{2+}$, inhibition of linoleic acid peroxidation and inhibition of lipoxygenase.

Conclusions. This study demonstrated that the methanolic extracts obtained from different types of coffee exhibit potential anti-inflammatory and antioxidant properties. The highest antioxidant activity was shown by traditionally roasted coffees from Colombia and Ethiopia.
\end{abstract}

Key words: coffee, coffee roasting, phenolic compounds, antioxidant activity

\section{INTRODUCTION}

Phytochemical contents in diets have gained attention because of their affect on the human body by improving health and well-being and/or by reducing the risk of disease, particularly lifestyle diseases. It is well known that the bioactive compound content in plant foods is generally affected by genetic, environmental and technological factors. The harvesting methods, storage conditions and technological processes occurring in food production may also affect phytochemical content and activity. Moreover, thermal processes in food production, in particular, can affect biological activities as a result of various chemical changes during heat-treatment (Evangelista et al., 2014; Kothe et al., 2013).

Coffee is one of the most widely consumed beverages in the world due to its sensory characteristics, 
stimulating and beneficial health effects (Pérez-Martínez et al., 2010; Rodrigues et al., 2013). Coffee is believed to be the most important source of natural antioxidants in our diet, e.g. phenolic compounds, alkaloids, mainly caffeine, diterpenes (cafestol and kahweol) and Maillard reaction products formed during roasting (Budryn and Nebesny, 2008). In coffee production, roasting is the process which markedly affects the composition of coffee beans. In traditional coffee roasting the number of beans is lower during a single roasting, beans are much more selected than in the industrial process and a lower temperature and longer time period is applied. Changes in the antioxidative capacity of coffee on roasting may be associated with the degradation of phenolic acids, but some researchers attribute the antioxidative effectiveness of roasted coffee to Maillard reaction products (Pérez-Hernández et al., 2012). Temperature and time are the critical parameters of the roasting process which modulate the chemical composition and physiological activity of the final products (Summa et al., 2007; Toci et al., 2009).

Thus, in this study the antioxidant activity of extracts was determined from coffee $(C$. arabica $\mathrm{L}$.) roasted traditionally (from Colombia, Ethiopia, Kenya and Brazil) and industrially (from Brazil).

\section{MATERIAL AND METHODS}

\section{Chemicals}

Ferrozine (3-(2-pyridyl)-5,6-bis-(4-phenyl-sulphonic acid)-1,2,4-triazine), ABTS (2,2'-azino-bis (3-ethylbenzthiazoline-6-sulphonic acid), ferric thiocyanate, Folin-Ciocalteau reagent, linoleic acid, gallic acid, phenolics standard, caffeine and lipoxygenase were purchased from Sigma-Aldrich (Poznań, Poland). All other chemicals were of analytical grade.

\section{Material}

Analyses were conducted on four samples of traditionally roasted coffee beans $(C$. arabica $\mathrm{L}$.): $\mathrm{C}-\mathrm{Colom}-$ bia, E - Ethiopia, $\mathrm{K}$ - Kenya and B - Brazil obtained from "Cofeina Romuald Zalewski Sp. j." (Poland) and one sample of industrially roasted coffee beans $(C$. arabica $\mathrm{L}$.) from Brazil (T), which was purchased in a local supermarket.

Coffee extract preparation. The beans of individual coffee samples were ground using the laboratory hammer mill (POLYMIX-Micro-Hammermill MFC, Kinematica AG, Littau/Lucerne, Switzerland) equipped with round holes $3.0 \mathrm{~mm}$. The detailed procedure of the grinding method and grinding equipment was described by Dziki et al. (2014). This ground material was then used in the preparation of aqueous and hydroalcoholic (methanolic) extracts.

The hydroalcoholic extracts were prepared using the following protocol: one gram of each kind of coffee was extracted with $50 \mathrm{~mL}$ of $50 \%(\mathrm{v} / \mathrm{v})$ methanol for $60 \mathrm{~min}$ at room temperature, and then centrifuged at $9000 \mathrm{~g}$ for $15 \mathrm{~min}$.

The aqueous extracts were prepared according to Budryn et al. (2009) with a slight modification. Briefly, one gram of each kind of analyzed coffee was brewed with boiling water followed by intermittent mixing thereafter to cool the mixture down and this was extracted with $50 \mathrm{~mL}$ of water for $60 \mathrm{~min}$ at room temperature and then centrifuged at $9000 \mathrm{~g}$ for 15 min (Budryn et al., 2009). The aqueous extracts were freeze-dried and hydroalcoholic extracts were dried convectively at $80^{\circ} \mathrm{C}$ in a laboratory dryer. To compare the contents of the quantified compounds in the extracts, dry extract weight was determined as the loss in weight after drying at $103^{\circ} \mathrm{C}$ until constant weight.

\section{Analytical methods}

Total phenolic content (TPC). The amount of total phenolic was determined using the Folin-Ciocalteau reagent (Singleton et al., 1974). The total phenolic content was calculated as gallic acid equivalent (GAE) in mg per $g$ of dry weight (DW).

Determination of caffeine content. The amount of caffeine in the coffee extracts was determined spectrophotometrically according to the method described by Singh and Sahu (2006). A standard curve was prepared in the concentration range $0.02-0.2 \mathrm{mg} / \mathrm{ml}$ of pure caffeine $\left(r^{2}=0.978\right)$.

Antioxidant activity assays. Free radical-scavenging activity was determined by the $\mathrm{ABTS}^{\circ+}$ method according to Re et al. (1999). Iron chelating activity and ferric reducing antioxidant power were determined according to the methods described by Guo et al. (2001) and Oyaizu (1986), respectively. Inhibition of lipid peroxidation was performed in accordance with Kuo et al. (1999). Antioxidant activities (except reducing power) were determined as $\mathrm{EC}_{50}-$ extract 
concentration (mg DW/mL) provided $50 \%$ of activity based on a dose-dependent mode of action. For reducing power $(\mathrm{RP}) \mathrm{EC}_{50}$ value $(\mathrm{mg} / \mathrm{mL})$ is the effective concentration at which the absorbance was 0.5 and it was obtained by interpolation from linear regression analysis.

Inhibition of lipoxygenase (LOX) activity. The ability to inhibit lipoxygenase (LOX) was determined according to the Szymanowska et al.'s method (2009). LOX inhibitory activity was determined as $\mathrm{EC}_{50}$ - the extract concentration $(\mathrm{mg} \mathrm{DW} / \mathrm{mL})$ that reduced activity by $50 \%$.

Statistical analysis. The experiments were conducted three times and all determinations were performed in triplicate. Statistical analysis was performed using STATISTICA 7.0 for mean comparison using Tukey's test at a significance level of $\alpha=0.05$.

\section{RESULTS}

The total content of phenolic compounds (TPC) determined in the Folin-Ciocalteu assay is shown in Figure 1. There were no statistically significant differences between aqueous and methanolic extracts in almost all samples. Only in the industrially roasted coffee (T) was the TPC determined in the methanolic extract significantly higher (about 30\%) than that of the aqueous extract (Fig. 1). The hydroalcoholic extract of coffee $\mathrm{T}$ was characterized by the highest TPC (650.96 $\pm 37.69 \mathrm{mg} \mathrm{GAE} / \mathrm{g} \mathrm{DW})$. However, comparing the water extracts, those of traditionally roasted coffees from Kenya and Ethiopia contained the largest amounts of phenolics $-461.63 \pm 40.23 \mathrm{mg} \mathrm{GAE} / \mathrm{g}$ DW and $448.996 \pm 35.25 \mathrm{mg} \mathrm{GAE} / \mathrm{g} \mathrm{DW}$, respectively.

The caffeine content (mg/g DW) in the coffee extracts is shown in Figure 2. In all aqueous traditionally roasted coffee extracts, similar levels of the alkaloid were observed (on average $136.14 \mathrm{mg} / \mathrm{g} \mathrm{DW}$ ). In aqueous extracts of industrially roasted coffee $(\mathrm{T})$ a significantly higher caffeine content was found (170.93 $\pm 11.74 \mathrm{mg} / \mathrm{g}$ DW). In the case of caffeine content in methanolic extracts, the lowest content $(212.48 \pm 2.31$ $\mathrm{mg} / \mathrm{g} \mathrm{DW}$ ) was determined in traditionally roasted coffee from Brazil, while the highest was noted in coffees from Columbia and Ethiopia (321.94 \pm 24.43 and $339.39 \pm 3.34 \mathrm{mg} / \mathrm{g} \mathrm{DW}$, respectively). Generally, in

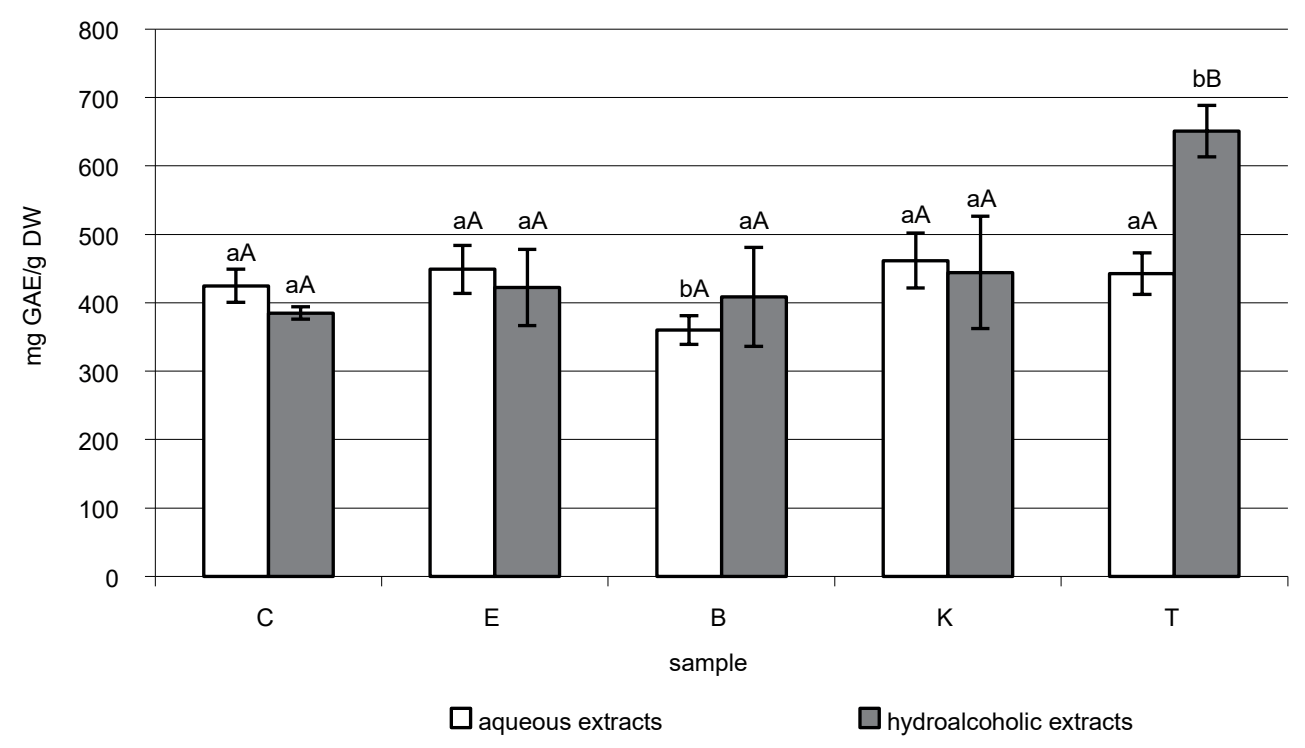

Fig. 1. Total phenolic content of extracts obtained from traditionally roasted coffee beans - from Colombia $-\mathrm{C}$, Ethiopia - E, Kenya $-\mathrm{K}$ and Brazil - B and industrially roasted coffee beans from Brazil - T. All values are mean standard deviation for triplicate experiments. Different lower case letters in the same types of coffee indicate a significant difference $(\alpha=0.05)$. Different capital letters in the same solvent used indicate a significant difference $(\alpha=0.05)$ 


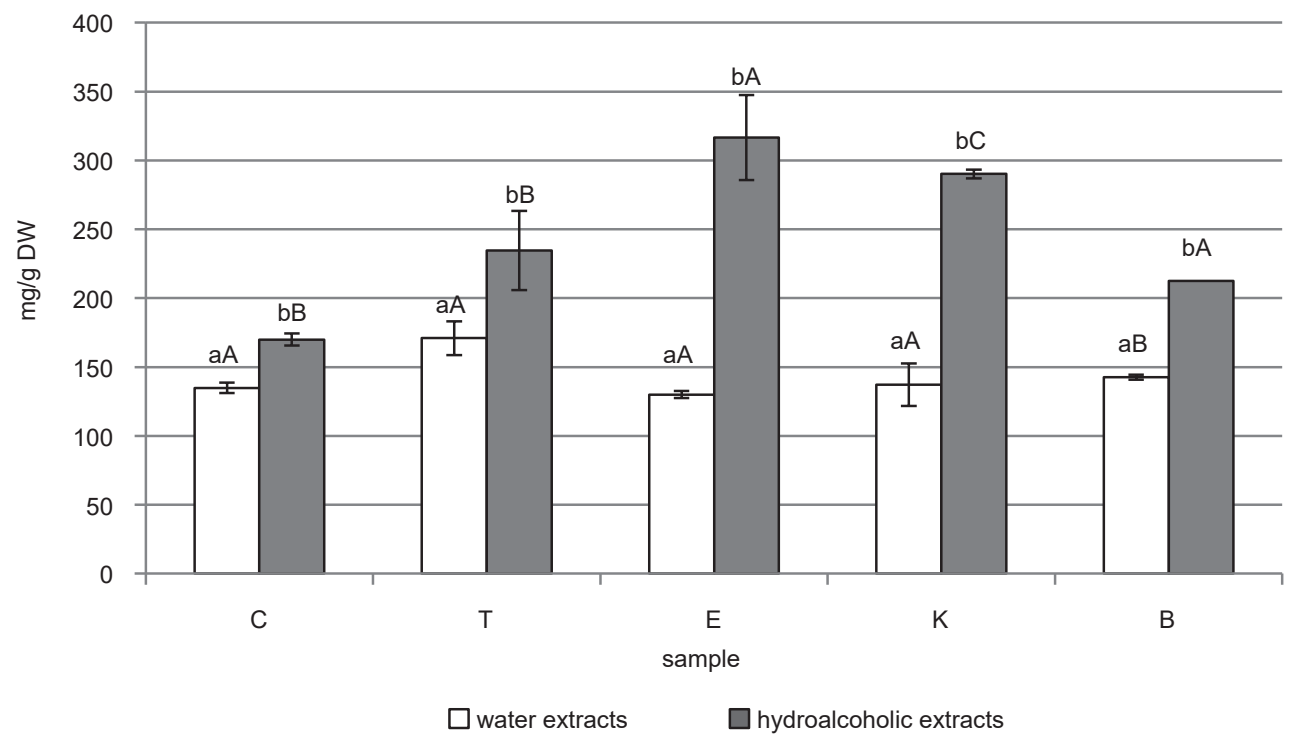

Fig. 2. Caffeine content $(\mathrm{mg} / \mathrm{g} \mathrm{DW})$ in extracts obtained from traditionally roasted coffee beans - from Colombia - C, Ethiopia - E, Kenya - K and Brazil - B and industrially roasted coffee beans from Brazil $-\mathrm{T}$. All values are mean standard deviation for triplicate experiments. Different lower case letters in the same types of coffee indicate a significant difference $(\alpha=0.05)$. Different capital letters in the same solvent used indicate a significant difference $(\alpha=0.05)$

all methanolic extracts the caffeine content was on average twice as high as in aqueous extracts (Fig. 2).

The antioxidant activity of hydroalcoholic and aqueous extracts of the kinds of coffees studied were determined using four different assays: iron chelating activity, reducing power, inhibition of lipid peroxidation and ABTS free radicals scavenging activity (Table 1). The coffees showed relatively high antiradical activity $-\mathrm{EC}_{50}$ values ranged from $1.26 \pm 0.04$ to $2.91 \pm 0.02 \mathrm{mg} \mathrm{DW} / \mathrm{mL}$ (Table 1). The aqueous extracts of all traditionally roasted coffees showed higher antiradical activity than the methanolic extracts, expect for hydroalcoholic extract from industrially roasted coffee $(\mathrm{T})$ (Table 1). The highest ability to scavenge free radicals $\left(\mathrm{ABTS}^{\cdot+}\right)$ was determined for aqueous extract $\mathrm{C}\left(\mathrm{EC}_{50}=1.26\right.$ $\pm 0.04 \mathrm{mg} \mathrm{DW} / \mathrm{mL})$ and $\mathrm{E}\left(\mathrm{EC}_{50}=1.30 \pm 0.02 \mathrm{mg} \mathrm{DW} /\right.$ $\mathrm{mL}$ ). The antioxidant activity expressed as chelating ability was relatively low in aqueous extracts. The highest $\mathrm{EC}_{50}$ value $(659.9 \pm 9.58 \mathrm{mg} \mathrm{DW} / \mathrm{mL})$ was observed for aqueous extract sample T. Moreover, for hydroalcoholic extracts the T sample showed the lowest $\mathrm{Fe}^{2+}$ chelating activity. The highest activity
$\left(\mathrm{EC}_{50}=1.79 \pm 0.016 \mathrm{mg} \mathrm{DW} / \mathrm{mL}\right)$ was determined for methanolic sample $\mathrm{C}$ (Table 1). Reducing power was significantly higher for hydroalcoholic extracts in all coffees tested in comparison to the aqueous extracts (Table 1). It should be noted that the hydroalcoholic extracts of all the coffees were also characterized by a relatively high and similar antioxidant activity expressed as reducing power (there were no statistically significant differences between the C, E, $\mathrm{B}, \mathrm{K}$ and $\mathrm{T}$ samples).

Hydroalcoholic extracts of all the coffees were characterized by a significantly greater ability to protect lipids against oxidation than was the case with aqueous extracts (Table 1). The activity of all aqueous extracts was relatively low $\left(\mathrm{EC}_{50}\right.$ values ranged from $35.62 \pm 5.25$ to $60.00 \pm 3.56 \mathrm{mg} \mathrm{DW} / \mathrm{mL}$ ), whereas methanolic extracts were characterized by a relatively high ability to inhibit linoleic acid peroxidation, especially the $\mathrm{C}, \mathrm{E}$ and $\mathrm{T}$ samples $\left(\mathrm{EC}_{50}=1.34 \pm 0.35,1.95\right.$ \pm 0.21 and $1.07 \pm 0.3 \mathrm{mg} \mathrm{DW} / \mathrm{mL}$, respectively).

As shown in Table 1, all the types of coffee studied were a good source of lipoxygenase (LOX) inhibitors, but it should be noted that hydroalcoholic extracts of 
Złotek, U., Karaś, M., Gawlik-Dziki, U., Szymanowska, U., Baraniak, B., Jakubczyk, A. (2016). Antioxidant activity of the aqueous and methanolic extracts of coffee beans (Coffea arabica L.). Acta Sci. Pol. Technol. Aliment., 15(3), 281-288. DOI: 10.17306/J. AFS.2016.3.27

Table 1. Antioxidant potential $-\mathrm{EC}_{50}(\mathrm{mg} \mathrm{DW} / \mathrm{ml}$ - of traditionally roasted coffee beans - from Colombia $-\mathrm{C}$, Ethiopia $-\mathrm{E}$, Kenya $-\mathrm{K}$ and Brazil $-\mathrm{B}$ and industrially roasted coffee beans from Brazil $-\mathrm{T}$ )

\begin{tabular}{|c|c|c|c|c|c|c|}
\hline & \multirow[t]{2}{*}{ Sample } & ABTS & $\begin{array}{l}\text { Iron chelating } \\
\text { activity }\end{array}$ & $\begin{array}{c}\text { Ferric reducing } \\
\text { power }\end{array}$ & $\begin{array}{l}\text { Inhibition of } \\
\text { linoleic acid } \\
\text { peroxidation }\end{array}$ & $\begin{array}{c}\text { Inhibition of } \\
\text { lipoxygenase } \\
\text { (LOX) }\end{array}$ \\
\hline & & \multicolumn{5}{|c|}{$\mathrm{EC}_{50}, \mathrm{mg} \mathrm{DW} / \mathrm{ml}$} \\
\hline \multirow[t]{2}{*}{$\mathrm{C}$} & aqueous & $1.26 \pm 0.049 \mathrm{Aa}$ & $43.74 \pm 3.25 \mathrm{Aa}$ & $6.27 \pm 1.2 \mathrm{Aa}$ & $58.12 \pm 2.35 \mathrm{Ab}$ & $97.77 \pm 18.36 \mathrm{Aa}$ \\
\hline & hydroalcoholic & $1.98 \pm 0.024 \mathrm{Bb}$ & $1.79 \pm 0.016 \mathrm{Ba}$ & $0.31 \pm 0.015 \mathrm{Ba}$ & $1.34 \pm 0.35 \mathrm{Ba}$ & $5.64 \pm 2.01 \mathrm{Ba}$ \\
\hline \multirow[t]{2}{*}{$\mathrm{E}$} & aqueous & $1.3 \pm 0.093 \mathrm{Aa}$ & $82.77 \pm 4.5 \mathrm{Ac}$ & $5.32 \pm 0.98 \mathrm{Aa}$ & $38.43 \pm 4.56 \mathrm{Aa}$ & $77.73 \pm 15.35 \mathrm{Aa}$ \\
\hline & hydroalcoholic & $2.12 \pm 0.019 \mathrm{Bb}$ & $2.07 \pm 0.15 \mathrm{Bab}$ & $0.3 \pm 0.023 \mathrm{Ba}$ & $1.95 \pm 0.21 \mathrm{Bb}$ & $4.56 \pm 1.98 \mathrm{Ba}$ \\
\hline \multirow[t]{2}{*}{ B } & aqueous & $1.66 \pm 0.079 \mathrm{Ac}$ & $68.76 \pm 4.56 \mathrm{Ab}$ & $6.19 \pm 0.85 \mathrm{Aa}$ & $39.03 \pm 4.02 \mathrm{Aa}$ & $146.6 \pm 16.35 \mathrm{Ab}$ \\
\hline & hydroalcoholic & $2.91 \pm 0.025 \mathrm{Aa}$ & $2.53 \pm 0.26 \mathrm{Bbc}$ & $0.31 \pm 0.017 \mathrm{Ba}$ & $15.79 \pm 1.05 \mathrm{Bc}$ & $5.18 \pm 1.57 \mathrm{Ba}$ \\
\hline \multirow[t]{2}{*}{ K } & aqueous & $1.39 \pm 0.03 \mathrm{Aab}$ & $154.34 \pm 7.89 \mathrm{Ad}$ & $6.86 \pm 0.89 \mathrm{Aa}$ & $60 \pm 3.56 \mathrm{Ab}$ & $200.2 \pm 13.25 \mathrm{Ad}$ \\
\hline & hydroalcoholic & $2.87 \pm 0.018 \mathrm{Ba}$ & $2.42 \pm 0.031 \mathrm{Bc}$ & $0.25 \pm 0.024 \mathrm{Bb}$ & $19.71 \pm 1.42 \mathrm{Bd}$ & $12.94 \pm 2.14 \mathrm{Bb}$ \\
\hline \multirow[t]{2}{*}{$\mathrm{T}$} & aqueous & $1.45 \pm 0.048 \mathrm{Ab}$ & $659.9 \pm 9.58 \mathrm{Ae}$ & $7.57 \pm 1.4 \mathrm{Aa}$ & $35.62 \pm 5.25 \mathrm{Aa}$ & $169.96 \pm 14.21 \mathrm{Ac}$ \\
\hline & hydroalcoholic & $1.38 \pm 0.015 \mathrm{Bc}$ & $7.6 \pm 0.31 \mathrm{Bd}$ & $0.3 \pm 0.018 \mathrm{Ba}$ & $1.07 \pm 0.3 \mathrm{Ba}$ & $3.55 \pm 1.57 \mathrm{Ba}$ \\
\hline
\end{tabular}

All values are mean standard deviation for triplicate experiments. Different lower case letters in the same types of coffee indicate a significant difference $(\alpha=0.05)$. Different capital letters in the same solvent used indicate a significant difference $(\alpha=0.05)$.

all samples had a higher ability to inhibit LOX. The highest LOX inhibition was observed for the T methanolic extract sample $\left(\mathrm{EC}_{50}=3.55 \pm 1.57 \mathrm{mg} \mathrm{DW} / \mathrm{mL}\right)$, while the lowest LOX inhibition was obtained for hydroalcoholic extract sample $\mathrm{K}\left(\mathrm{EC}_{50}=12.94 \pm 2.14 \mathrm{mg}\right.$ $\mathrm{DW} / \mathrm{mL})$. Another tested methanolic extract of coffee beans also showed high inhibition LOX activity (Table 1).

\section{DISCUSSION}

Coffee is one of the most popular beverages consumed by millions of people every day and is traditionally used for hedonistic and psychostimulant purposes. Until recently, its composition was not considered as a healthy dietary supplement and it was not linked with cardiovascular diseases and an increased risk of myocardial infarction. Currently, coffee is considered as a rich source of bioactive compounds with antioxidant activity such as the hydroxycinnamic acids family: caffeic, chlorogenic, coumaric, ferrulic and sinapic acids (Farah et al., 2006; O'Keefe et al., 2013). There are two types of techniques used in coffee production: wet and dry processes. Most of the world's green coffee has experienced some form of wet processing; this includes most premium products. The amount of bioactive compounds and taste of coffee depend on bean origin, roasting and the methods for preparing the drink (Afify et al., 2011). The roasting process is particularly important and it may lead to the formation of new Maillard reaction products that influence the antioxidant properties of coffee (O'Keefe et al., 2013). There are traditional and industrial methods of roasting, which differ in terms of temperature, time and the manner of blowing hot air. Traditional methods often use old, wood-fired coffee roasters made from cast iron. Many studies have demonstrated the benefits of coffee consumption, the chemical compounds of coffee beans, the relationship between coffee consumption and its potential disease prevention properties, which might be due to their polyphenol content (Huxley et al., 2009; O'Keefe et al., 2013; Ota et al., 2010) However, there has been little research into the relationship between polyphenol content and the antioxidant properties of coffee extracts prepared using different roast processes. 
The present study compared the antioxidant activity of coffee roasted using traditional and industrial techniques. We studied aqueous and hydroalcoholic extracts from five kinds of coffee beans. In our study, the phenolic content was significantly higher than that obtained by other authors, because those results were calculated on the basis of the dry weight of lyophilized extract and not on the dry weight of coffee beans. TPC in a hot aqueous extract from Abd El-Maboed coffee was $1.87 \mathrm{mg} / \mathrm{g}$ DW. However, in the same sample prepared in cold water TPC was $2.28 \mathrm{mg} / \mathrm{g}$ DW (Afify et al., 2011). Ramalakshmi et al. (2009) studied the total phenolic content in five different aqueous extracts from coffee beans. The amount of these compounds was ranged from $1-4.5 \mathrm{mg} / \mathrm{g}$ DW. The reasons for the different phenolic content in the samples could be either the degradation of these compounds during roasting or the release of these compounds during extraction (Ramalakshmi et al., 2009). The data also show that the TPC in the extract depends on the origin of the coffee beans and type of solvent.

The most frequently cited roasted coffee bean ingredient is caffeine. Caffeine is the main alkaloid in coffee beans, accounting for 1 to $4 \%$ (dry basis), with a large variation within cultivars and among them. Caffeine content is strongly related to the quality of coffee beverages, because it contributes to its bitterness. We showed a high caffeine content in hydroalcoholic extracts (Fig. 2). Our results agreed with a study by Perva-Uzunalić et al. (2006), when caffeine extraction efficiency was better in case of using methanol than water at boiling point. Franca et al. (2005) indicate that caffeine content decreases significantly during the roasting of coffee beans and is about $0.6 \mathrm{~g} / 100 \mathrm{~g}$ DW. Caffeine content in coffee varies widely, depending on the type of coffee bean and the method of preparation used (Perez-Hernández et al., 2012).

Moreover, the method of coffee bean roasting affects the antioxidant activity of coffee extracts. It has been found that medium roasted coffee beans have the highest activity, due to the balance between the degradation of phenolic compounds and products of Maillard reaction during the process (Bekedam et al., 2008; Del Castillo et al., 2005; Sacchetti et al., 2009). However, the origin of the coffee beans affects the antioxidant activity. Budryn and Nebesny (2008) showed that
Robusta coffee extracts had higher antioxidant efficacy than Arabica coffee beans.

Our results show that both aqueous and methanolic extracts possess antiradical potential. The highest activity was determined in $\mathrm{C}$ and $\mathrm{E}$ aqueous extracts. In the case of hydroalcoholic extracts, the most effective scavenger against $\mathrm{ABTS}^{\cdot+}$ was obtained from the industrial roasting technique. On the basis of these results, it should be noted that hydrophilic compounds are effective free radical scavengers. Pérez-Hernández et al. (2012) found no statistically significant differences in free radical scavenging against ABTS of Arabica, Caracoli and Robusta green coffee beans and of four commercially available coffee types (Italian roast, French roast, torrefacto and instant coffee). Moreover, in the present study the antioxidant properties depended on the coffee beans' origin and roasting technique used. This suggests that compounds with antioxidant properties are changed during the preparation of the coffee beans and that the antioxidant properties of coffee extracts can be maintained, or even enhanced, by the development of compounds with antioxidant activity, including Maillard reaction products (Budryn and Nebesny, 2008). Sacchetti et al. (2009) examined correlations between coffee roasting degree and free radical scavenging activity. They conclude that at higher roasting intensities, the thermal degradation of polyphenols causes a decrease in antioxidant activity and this process is not counterbalanced by further Maillard reaction products. Górnaś et al. (2016) concluded that phenolic acids are the main group of phenolics indicated in coffee beans. A reduction in its concentration is a result of their thermal instability and degradation during intense roasting. The antioxidant activity of coffee samples depends on phenolic content, so roasting intensity can affect the ability to scavenge free radicals, reduction power or the ability to chelate transition metal ions. In general, light-roasted coffee possesses higher antioxidant activity than dark-roasted.

The ability to chelate $\mathrm{Fe}^{2+}$ and the reducing power of a compound serve as significant indicators of its potential antioxidant activity (Hseu et al., 2008). In this study, all coffee extracts presented the ability to chelate $\mathrm{Fe}^{2+}$ and the reducing power of compound. These properties were higher for methanolic than aqueous extracts. However, a higher reducing power 
was determined for aqueous than for hydroalcoholic extracts of traditionally roasted coffee beans from Brazil. The results of our paper show that lipophilic compounds of coffee significantly affect the ability to chelate $\mathrm{Fe}^{2+}$ and reducing power.

Iron can stimulate lipid peroxidation by the Fenton reaction and it could lead to the transformation of lipid hydroperoxides into peroxyl and alkoxyl radicals that can perpetuate a chain reaction. The ability to chelate metal ions, especially iron reduces the concentration of the transition metal that catalyzes lipid peroxidation (Mohan et al., 2012). Many authors investigated phenolic compounds with antioxidant activities and the inhibition of linoleic acid peroxidation or LOX inhibition (Gawlik-Dziki, 2012; Szymanowska et al., 2009; 2004), while there is the lack of research on coffee extracts obtained from beans roasted with traditional and industrial techniques. In the study, inhibition of linoleic acid peroxidation and LOX inhibition were determined. Hydroalcoholic extracts from $\mathrm{C}$ and $\mathrm{T}$ were the most effective preventers of linoleic acid and inhibition of lipoxygenase. It should be noted that LOX is a pro-oxidative and pro-inflammatory enzyme, so its inhibition plays a very important role in inflammatory and cancer prevention (Gawlik-Dziki, 2012). Additionally, the high chelating power of coffee samples may offer anti-atherosclerotic potential (O'Keefe et al., 2008).

\section{CONCLUSIONS}

This study demonstrated that the hydroalcoholic extracts obtained from different types of coffee exhibit potential anti-inflammatory and antioxidant properties. The highest antioxidant activity was shown by traditionally roasted coffees from Colombia and Ethiopia. The differences in antioxidant activity of coffee bean extracts evaluated through four complementary assays (free radical scavenging activity against ABTS, iron chelating activity, ferric reducing power, inhibition of linoleic acid peroxidation) are the result of changes in phenolic profiles, which depends on intensity of roasting process. Dark-roasted coffee possesses lower antioxidant capacity than light-roasted. Moreover, there was no clear correlation between the process of coffee bean roasting and the source or type of coffee.

\section{ACKNOWLEDGMENTS}

The authors gratefully acknowledge "Cofeina Romuald Zalewski Sp. j." (Poland) for providing samples of traditionally roasted coffees.

\section{REFERENCES}

Afify, A. E.-M. M. R., Shalaby, E. A., El-Beltagi, H. S. (2011). Antioxidant activity of aqueous extracts of different caffeine products. J. Med. Plants Res., 5, 5071-5078.

Bekedam, E. K., Schols, H. A., Cämmerer, B., Kroh, L. W., van Beokel, M. A. J. S., Smit, G. (2008). Electron spin resonance (ESR) studies on the formation of roasting-induced antioxidative structures in coffee brews at different degrees of roast. J. Agric. Food Chem., 56, 4597-4604.

Budryn, G., Nebesny, E. (2008). Antioxidant properties of Arabika and Robusta coffee extract preparated under different conditions. Deut. Lebensm-Rundsch., 104, 69-78.

Budryn, G., Nebesny, E., Podsędek, A., Żyżelewicz, D., Materska, M., Jankowski, S. Janda, B. (2009). Effect of different extraction methods on the recovery of chlorogenic acids, caffeine and Maillard reaction products in coffee beans. Eur. Food Res. Technol., 228, 913-922.

Del Castillo, M. D., Gordon, M. H., Ames, J. M. (2005). Peroxyl radical-scavenging activity of coffee brews. Eur. Food Res. Technol., 221, 471-477.

Dziki, D., Cacak-Pietrzak, G., Miś, A., Jończyk, K., Gawlik-Dziki, U. (2014). Influence of wheat kernel physical properties on the pulverizing process. J. Food Sci. Technol., 51, 2648-2655.

Evangelista, S. R., Silva, C. F., Pedrozo da Cruz Miguel, M. G., de Souza Cordeiro, C., Pinheiro, A. C. M., Duarte, W. F., Schwan, R. F. (2014). Improvement of coffee beverage quality by using selected yeasts strains during the fermentation in dry process. Food Res. Int., 61, 183-195.

Farah, A., Donangelo, C. M. (2006). Phenolic compounds in coffee. Braz. J. Plant Physiol., 18, 26-36.

Franca, A. S., Mendonça, J. C. F., Oliveira, S. D. (2005). Composition of green and roasted coffees of different cup qualities. LWT - Food Sci. Technol., 38, 709-715.

Gawlik Dziki, U. (2012). Dietary spices as a natural effectors of lipoxygenase, xanthine oxidase, peroxidase and antioxidant agents. LWT - Food Sci. Technol., 47, 138-146.

Górnaś, P., Dwiecki, K., Siger, A., Tomaszewska-Gras, J., Michalak, M., Polewski, K. (2016). Contribution of 
Złotek, U., Karaś, M., Gawlik-Dziki, U., Szymanowska, U., Baraniak, B., Jakubczyk, A. (2016). Antioxidant activity of the aqueous and methanolic extracts of coffee beans (Coffea arabica L.). Acta Sci. Pol. Technol. Aliment., 15(3), 281-288. DOI: 10.17306/J. AFS.2016.3.27

phenolic acids isolated from green and roasted boiledtype coffee brews to total coffee antioxidant capacity. Eur. Food Res. Technol., 242, 641-653.

Guo, J.-T., Lee, H.-L., Chiang, S.-H., Lin, H.-I., Chang, C.-Y. (2001). Antioxidant properties of the extracts from different parts of broccoli in Taiwan. J. Food Drug. Anal., 9, 96-101.

Huxley, R., Lee, C. M., Barzi, F., Timmermeister, L., Czernichow, S., Perkovic, V., Grobbee, D. E., Batty, D., Woodward, M. (2009). Coffee, decaffeinated coffee, and tea consumption in relation to incydent type 2 diabetes mellitus: A systematic review with meta-analysis. JAMA Intern. Med., 169, 2053-2063.

Hseu, Y. C., Chang, W. H., Chen, C. S., Liao, J. W., Huang, C. J., Lu, F. J., Chia, Y. C., Hsu, H. K., Wu, J. J., Yang, H. L. (2008). Antioxidant activities of Toona Sinensis leaves extracts using different antioxidant models. Food Chem. Toxicol., 46, 105-114.

Kothe, L., Zimmermann, B. F., Galensa, R. (2013). Temperature influences epimerization and composition of flavanol monomers, dimers and trimers during cocoa bean roasting. Food Chem., 141, 3656-3663.

Kuo, J. M., Yeh, D. B., Pan, B. S. (1999). Rapid photometric assay evaluating antioxidative activity in edible plant material. J. Agric. Food Chem., 47, 3206-3209.

Mohan, S. C., Balamurugan, V., Salini, S. T., Rekha, R. (2012). Metal ion chelating activity and hydrogen peroxide scavenging activity of medicinal plant Kalanchoe pinnata. J. Chem. Pharm. Res., 4, 197-202.

O’Keefe, J. H., Bhatti, S. K., Patil, H. R., Dinicolantonio, J. J., Lucan, S. C., Lavie, C. J. (2013). Effects of habitual coffee consumption on cardiometabolic disease, cardiovascular health, and all-cause mortality. J. Am. Coll. Cardiol., 17, 1043-1051.

Ota, N., Soga, S., Murase, T., Shimotoyodome, A., Hase, T. (2010). Consumption of coffee polyphenols increases fat utilization in humans. J. Health Sci., 56, 745-751.

Oyaizu, M. (1986). Studies on products of browning reaction - antioxidative activities of products of browning reaction prepared from glucosamine. Jpn. J. Nutr., 44, 307-315.

Pérez-Martínez, L. M., Caemmerer, B., De Peña, M. P., Cid, C., Kroh, L. W. (2010). Influence of brewing method and acidity regulators on the antioxidant capacity of coffee brews. J. Agric. Food Chem., 58, 2958-2965.

Pérez-Hernández, L. M., Chávez-Quiroz, K., Medina-Juárez, L. A., Meza, N. G. (2012). Phenolic characterization, melanoidins, and antioxidant activity of some commercial coffees from Coffea arabica and Coffea canephora. J. Mex. Chem. Soc., 56, 430-435.

Perva-Uzunalić, A., Ŝkerget, M., Knez, Ž., Weinreich, B., Otto, F., Grüner, S. (2006). Extraction of active ingredients from green tea (Camellia sinensis): Extraction efficiency of major catechins and caffeine. Food Chem., 96, 597-605.

Ramalakshmi, K., Mohan Rao, L. J. M., Takano-Ishikawa, Y., Goto, M. (2009). Bioactivities of low-grade green coffee and spent coffee in different in vitro model systems. Food Chem., 115, 79-85.

Re, R., Pellegrini, A., Proteggente, A., Pannala, M., Yang, M., Rice-Evans, C. (1999). Antioxidant activity applying an improved ABTS radical cation decolorization assay. Free Radic. Biol. Med., 26, 1231-1237.

Rodrigues, N. P., Benassi, M. T., Bragagnolo, N. (2013). Scavenging capacity of coffee brews against oxygen and nitrogen reactive species and the correlation with bioactive compounds by multivariate analysis. Food Res. Int. dx.doi.org/10.1016/j.foodres.2013.09.028

Sacchetti, G., Di Mattia, C., Pittia, P., Mastrocola, D. (2009). Effect of roasting degree, equivalent thermal effect and coffee type on the radical scavenging activity of coffee brews and their phenolic fraction. J. Food Eng., 90, 74-80.

Singh, D. K., Sahu, A. (2006). Spectrophotometric determination of caffeine and theophylline in pure alkaloids and its application in pharmaceutical formulations. Anal. Biochem., 349, 176-180.

Singleton, V. L., Orthofer, R., Lamuela-Raventos, R. M. (1974). Analysis of total phenols and other oxidation substrates and antioxidants by means of Folin-Ciocalteu reagent. Methods Enzymol., 299, 152-178.

Summa, C. A., de la Calle, B., Brohee, M., Stadler, R. H., Anklam, E. (2007). Impact of the roasting degree of coffee on the in vitro radical scavenging capacity and content of acrylamide. LWT - Food Sci. Technol., 40, 1849-1854.

Szymanowska, U., Jakubczyk, A., Baraniak, B., Kur, A. (2009). Characterisation of lipoxygenase from pea seeds (Pisum sativum var. Telephone L.). Food Chem., 116, 2906-2910.

Toci, A. T., Silva, C. M., Fernandes, F., Farah, A. (2009). Effect of the fluid speed changes on the chemical composition of coffee samples roasted in an industrial semi-fluidized bed roaster. In Proceedings of 23nd International Conference on Coffee Science. ASIC, 500-503. 2009. Trieste, Italy. 